\title{
Mathematical Reasoning Ability Through Learning Design Based on RME on The Flat Face Three Dimensional Object
}

\author{
$1^{\text {st }}$ Fadhilati Salma \\ Department of Mathematics, Faculty of Mathematics and \\ Natural Sciences, Universitas Negeri Padang \\ Padang, Indonesia \\ dhila salma@yahoo.com
}

\author{
$2^{\text {nd }}$ Ahmad Fauzan \\ Department of Mathematics, Faculty of Mathematics and \\ Natural Sciences, Universitas Negeri Padang \\ Padang, Indonesia \\ fauzan math@fmipa.unp.ac.id
}

\begin{abstract}
This study aims to look at the mathematical reasoning ability through the application of learning flow on the topic of flat face three-dimensional object using the Realistic Mathematics Education (RME) approach. The learning flow applied contains real problems which are the starting points for building students' knowledge in solving mathematical problems. Learning flow is developed through design research consisting of three stages, namely: preparing experiment, conducting experiment and retrospective analysis. The research subjects consisted of 22 fifth grade elementary school students in Padang, West Sumatera. The research data was collected through observation, interviews, checklist, and the results of the analysis of students' work. The results of the analysis of the data obtained show that reasoning ability can help students build their own knowledge in finding the concept of surface area and volume of flat face three-dimensional object through an RME-based learning flow .alysis shows that the configuration has a $94.85 \%$ similarity.
\end{abstract}

Keywords-RME, Learning Trajectory, Design Research

\section{INTRODUCTION}

The reasoning ability is an important component in education and is needed to understand mathematics specifically. Mathematical reasoning can be obtained at the elementary school level [1]. To achieve this, elementary students must be placed in situations where they can make, correct, and test their own guesses [2]. Mathematical reasoning refers to the ability to formulate and represent a given mathematical problem, and to explain and justify a solution or argument [3]. There is a direct relationship between reasoning ability and success in mathematics, where individuals who demonstrate good reasoning ability will display better problem-solving profiles with the interrelations they can identify, and also have better communication skills [4,5]. Therefore, mathematical reasoning ability is a very important ability to be given to students even since being in elementary school. Mathematical reasoning ability will help students to understand mathematics material and make it easier for students to learn mathematics at an advanced level.

The reasoning is a very important skill needed in mathematics [6]. The ability to think of children, especially children of primary school age are generally more real and teachers have a role in developing these abilities at a more abstract level, one of them with mathematical reasoning abilities. One of the materials taught in the elementary school curriculum is about geometry. Usually, in the introduction of volume measurements in class $\mathrm{V}$ elementary schools in Indonesia, it is done by first giving pictures of the arrangement of unit cubes without any previous concrete activities [7]. In volume measurement, the teacher immediately gives a volume formula then students use it to solve problems related to the concept of the given volume.

Supposedly, in geometric thinking students involve a cognitive process of visualization and reasoning [8]. Geometric reasoning refers to the act of "creating and using a formal conceptual system to investigate form and space". [9] Therefore, in order to understand mathematics especially the topic of geometry well, students should use reasoning skills to facilitate students in understanding the material being taught.

Given the importance of mathematical reasoning ability for students in understanding the mathematical material, it is necessary to improve these abilities. The reasoning ability can be improved through teaching methods [10]. In mathematics learning, the material is not only transferred by teachers to students. Students should not be considered as passive recipients who only accept concepts by simply using certain formulas and procedures to solve a problem, but students are given more opportunities and guided into situations to reinvent the concept in their own way. Learning about flat face three-dimensional object in a classroom is emphasized on the relationship between students' concepts and experiences every day. The role of teachers can be maximized by designing learning so that the atmosphere of learning becomes effective and on target that can make students have curiosity, think critically and creatively, be active, be able to understand math content well, be able to build knowledge with themselves and can solve problems with processes true and not only oriented towards the end result. Therefore, one way is to use the learning path.

Learning design based on learning trajectory is known as Hypothetical Learning Trajectory (HLT) which is a learning flow consisting of learning objectives, learning activities, and learning process hypotheses to predict how students' thoughts and understanding will develop in the 
context of learning activities [11 ] The reasoning ability of students taught with RME is better than students taught conventionally [12]. It was explained again that this was triggered by the horizontal and vertical mathematical processes carried out in solving contextual problems in the RME. Other studies that show that the RME not only enhances students 'reasoning abilities but also improves students' mathematical thinking skills, such as research conducted by Graveimeijer, which shows that HLT with the RME approach helps teachers in developing appropriate learning theories for a topic.

When students are connected to the context (everyday problems), students can understand what they are doing, and do not need to memorize concepts and procedures that are meaningless to them [13]. Learning like this is a good start for students in the process towards more formal knowledge. Mathematical learning should be associated with concrete objects that are easily found in students in everyday life so that students are easily understood without having to memorize formulas and procedures that are difficult for students. When children learn separately from their daily life experiences, children will quickly forget and cannot apply mathematics [14].

Human activities related to real life, real terms not only mean according to facts but also mean as a situation the problems faced by students have meaning for them. For that, it is necessary to explore various situations or contexts that are adapted to students' cognitive abilities in mathematics learning. Based on the background of the above problems, a research was carried out to develop a Realistic Mathematics Education (RME) Based Learning Design for Topics in Flat Face Three Dimensional Object in Class V SD / MI that is valid, practical and effective.

\section{RESEARCH METHODS}

This type of research is a development research by combining the Plomp model and the Gravemeijer \& Cobb model. To develop the learning path of Gravemeijer and Cobb models. The Gravemeijer and Cobb model consists of three phases, namely the phase that prepares for experiments, conducts experiments and retrospective analysis [15]. To develop products from learning design using the Plomp model. Plomp model consists of 3 phases, the initial investigation phase (the initial stage of the research), the development or prototype stage (prototyping stage) and the hottest phase (assessment phase) [16]. The initial investigation phase (preliminary research) consists of needs analysis, curriculum analysis, student analysis, analysis, and analysis. Based on the results of the analysis at the initial stage of the study, learning trajectory was designed to develop flat face three-dimensional object based on RME, for its operations to be designed by student books and teacher books.

In the prototyping stage phase, this prototype was made an assessment through formative evaluation. The learning design of the topic of flat face three-dimensional object based on RME that has been designed is selfevaluated and validated by experts. Device validation was carried out by three Mathematics lecturers, one Education Technology lecturer and one Indonesian lecturer. After the learning design was produced the topic of building a valid RME-based flat-side room, one-to-one evaluation, small group evaluation / 1 cycle conducting the experiment, followed by retrospective analysis and field trials (field test)) / 2 cycles conducting the experiment to see the practicality. In the assessment phase (assessment stage), an assessment of reasoning ability tests was carried out for fifth-grade students of SDN 30 Kuranji to see effectiveness. Research data was collected through validation sheets, teacher and student response questionnaire sheets, learning design implementation observation sheets, interview sheets, and students' mathematical reasoning ability tests.

\section{RESULTS AND DISCUSSION}

Research begins with a preliminary analysis. At this stage is carried out needs analysis, curriculum analysis, concept analysis, analyzing student characteristics and literature review. Based on needs analysis, curriculum analysis, analysis of students' concept analysis and review of the literature, a design was designed to topic flat face threedimensional object based on RME in class V SD / MI.

\section{A. Prototype Design.}

1) Hypothetical Learning Trajectory (HLT) Design.

At this stage the designed is Hypothetical Learning Trajectory (HLT), HLT is designed to adopt HLT Simon (1995) consisting of three parts, namely; learning objectives, activities and predictions of student answers, teacher anticipation, how students answer and the students' thinking process. The learning objectives here are intended targets or achievements that must be understood by students after they have completed a mathematical topic or concept. Learning objectives are set at the beginning and then followed by a series of activities and predictions of student answers and anticipation of answers by the teacher by giving inducement questions to achieve the learning objectives that have been set. The inducement question is given to stimulate students' thinking skills so that the learning objectives that are set can be achieved. Student activities and predictions of student answers are designed starting from the simple one then proceeding with more complex problems. This activity is expected to be able to develop horizontal mathematical capabilities towards vertical mathematical. Here is the rational HLT designed:

In the study of the topic of the flat face, the threedimensional object designed 2 HLT, first found the concept of surface area to flat face three-dimensional object through the activity of making boxes and opening boxes of packaging. The selection of this activity is because in the manufacture of boxes students can first understand the elements of the three-dimensional object and their properties. The material designed starts by finding the surface area of cubes, beams, triangular prisms and pyramid. The reason for choosing the cube that was taught first is because the cube is the simplest three-dimensional object, so students can easily find the surface area of the cube.

Second, the discovery of the concept of volume through the activity of calculating the matchbox 
arrangement. The calculation of the matchbox arrangement arranged in the form of a beam can stimulate students to find that the volume of cubes and beams can be calculated by multiplying the area of the base and height where the area of the base on the cube and beam is in the form of a quadrilateral. Through this concept, students can understand that to determine the volume of a triangular prism can use the same concept, namely the area of a high base, which is a triangular base.

\section{2) Designing Teacher Books and Student Books}

The teacher's book designed in this RME learning has several components. This component of the teacher book was designed to adopt the Mathematics In context (MIC) teacher's book on the Grasping Equation chapter (see National Science Foundation, 1998) and combined with the National Education Book writing. Components of the teacher's book are learning objectives, time allocation, mathematics, summaries, student ability assessment plans, student book pages and comments on problems. Whereas student books have components of learning objectives, student activities, contextual problems and understanding tests.

\section{B. Formative evaluation}

The purpose of the formative evaluation is to assess the quality of the product design developed, namely HLT, teacher books, and student books. The evaluation was conducted using formative evaluation developed by Tessmer (2013) consisting of expert validation, one-to-one interviews of students (one to one), small groups or simple evaluations (small group or micro evaluation), and field tests [17].

In the self-evaluation stage, many mistakes occur in typing errors, sentences that are not clear meaning, punctuation errors, image errors, and problems that have not been contextual. For example, in HLT, there is a problem that states the size of an $8 \mathrm{~cm}$ birthday cake box, where the size is too small for a birthday cake box. Errors in the picture, for example, say "keychain from flannel fabric", but there are no hangers on the picture. After self-evaluation of the learning design topic flat face three-dimensional object, based on RME that have been designed, further improvements are done.

1) Validation.

After self-evaluation stages, then, the learning design was validated by 5 validators, namely 3 mathematics expert lecturers, 1 education technology lecturer and 1 Indonesian lecturer. In HLT the aspects observed are aspects of content and language.

During the validation process, there are several revisions suggested by the validator. The overall value of the HLT validity is 3.38 with a very valid category. Thus it can be concluded that the HLT component aspect of the topic flat face three-dimensional object based on RME is valid.

Implementation products (teacher books and student books) are also validated. In the teacher's book, the observed aspects are aspects of content, aspects of language, didactic aspects or presentation and aspects of display or graphics.
The overall validity value of the teacher's book is 3,48 with a very valid category. Thus, it can be concluded that the designed RME-based Teacher's Book is valid.

In the student book, the observed aspects are aspects of content, aspects of language, didactic aspects or presentation and aspects of display or graphics. During the validation process, there are several revisions suggested by the validators. The overall validity value of the Teacher's Book is $80.72 \%$ with a very valid category. Thus, it can be concluded that the designed RME-based Teacher's Book is valid.

\section{2) Practicality}

After all, products are developed in a valid category, then an individual evaluation (one-to-one evaluation) is carried out with three class $\mathrm{V}$ students at Kuranji Elementary School 07 with low, medium and high abilities. Individual evaluations are conducted in 6 informal meetings outside of class hours. After that, an interview was conducted to ask students' responses to the learning flow in the book. Based on the results of interviews with students at the evaluation stage one on one, generally high, medium and low ability students can understand the contextual problems presented in contextual problems that are used as starting points in finding each concept.

After revising the results of individual evaluations, a small group evaluation is then carried out. This small group evaluation was carried out on 6 students of grade V SDN 07 karanji with high, medium and low abilities. After the product in the small group evaluation was revised, then a field test or field test was carried out. Field trials were carried out on grade V students of SDN 30 Kuranji. The difference between schools where individual evaluations are conducted, small groups and field tests is because only one local class is available for field testing, so classes are needed from other equivalent schools.

Overall the learning design of the topic flat face threedimensional object based on RME can already be used for learning flat face three-dimensional object based on RME. Large group trials (field tests) are also called second cycle conducting experiments. This learning begins with a class discussion, students sit in groups of 4-5 students, occasionally there are also students only discussion with friends in pairs (in pairs). This class discussion is aimed not only at building and developing students 'interactivity according to the characteristics of the RME but also as a stimulation of students' basic knowledge about the concept of flat face three-dimensional object.

The discovery of the cube surface area concept in this study was designed through two activities, namely the determination of the area of the glass in the manufacture of boxes and calculating the area of the birthday cake box. In finding the surface area of the beam, each group has a different answer because each group carries its own packaging box. Thus students can find out various ways to determine the surface area of the beam. students can construct their own understanding in finding the formula of the surface area of the beam.

The students' steps in finding the surface area of the triangular prism, students begin to calculate the side of the 
triangular prism. Followed by a quadrangular side. Some groups can calculate the surface area of the prism without the help of prism nets, some groups still use the help of nets to determine the surface area of the triangular prism.

The next activity is to find the surface area of the pyramid. In this activity is almost the same as the activities carried out by students in finding the surface area of triangular prisms. Some groups still need the help of the nets obtained from the display, while others can determine without the nets. The teacher together with students finds a formula to be mutually agreed upon.

Next is an activity to find prism volume. In finding the formula to calculate the prism volume, it begins with determining the volume of the beam. In these activities, students understand that to determine the volume of the beam is obtained from the area of the base multiplied by the height of the beam, where the area of the base is obtained by multiplying the length and width of the beam. After that student are led to find the cube and prism volume formulas.

The practicality value of the learning design on the topic flat face three-dimensional object obtained from the teacher questionnaire was 3.32 with a very practical category based on practicality criteria. Thus it can be concluded that the teacher considers the design learning of topic flat face three-dimensional object based on RME is practically used in the V class SD / MI.

The practicality value of the learning design on the topic flat face three-dimensional object obtained from the student questionnaire was 3.2 with a practical category based on practicality criteria. From the results of the questionnaire analysis filled by students, the design learning of topic flat face three-dimensional object is easy to use, interesting, well understood, can motivate students to learn mathematics and find concepts well. Thus it can be concluded that students consider the learning design of topic flat face three-dimensional object based on RME practical to be used in the construction of flat-side V classrooms in SD / MI.

\section{3) Effectiveness}

The learning design of topic flat face threedimensional object based on RME saw from the results of the students' mathematical reasoning ability test. Ability This mathematical reasoning can be seen from the ability of students to give opinions with different answers or strategies. Students learn from informal mathematics to formal mathematics. The process that occurs in finding concepts on the topic flat face three-dimensional object for each student varies. With the learning method applied, students can discuss and exchange opinions. The variety of answers and opinions expressed by students shows that student reasoning is increasing when compared to previous learning.

The success of achieving students' mathematical reasoning abilities is $77.27 \%$ with good criteria and as many as $77 \%$ of students have high reasoning abilities. Thus it was concluded that the design learning of topic flat face three-dimensional object based on RME class V SD / MI was effective in giving effect to students' mathematical reasoning ability.

After the learning process ends, researchers and teachers discuss the extent of the implementation of the learning device design. Overall, the learning design of topic flat face three-dimensional object based on RME can be used for learning flat face three-dimensional object.

\section{CONCLUSIONS}

Based on the results of the data analysis that has been done, it can be concluded that the learning design of topic flat face three-dimensional object based on RME class V$\mathrm{SD} / \mathrm{MI}$ designed to be valid, practical, and effective is used to improve students' mathematical reasoning abilities in the classroom. Based on the above conclusions, the design learning of topic flat face three-dimensional object based on RME in class V SD / MI can be used as a guide for teachers in implementing learning to improve students' mathematical reasoning skills.

\section{ACKNOWLEDGMENT}

The author would like to thank Mr. Prof.Dr.Ahmad Fauzan, M.Pd., M.Sc, as a supervisor and lecturer at the Padang State University Postgraduate who has provided guidance and direction with sincerity and patience in the completion of this article. This article is based on a thesis written by Fadhilati Salma entitled "Development of Learning Design Topics Flat Face Three Dimensional Object Based on Realistic Mathematics Education for Grade V SD / MI students".

\section{REFERENCES}

[1] National Council of Teachers of Mathematics (NCTM), Executive summary:Principles and standards for school mathematics. Reston, VA: NCTM, 2000.

[2] National Council of Teachers of Mathematics (NCTM), Executive summary:Principles and standards for school mathematics. Reston, VA: NCTM, 2000.

[3] Kilpatrick J, Swafford J \& Findell B, Adding It Up: Helping Children Learn Mathematics. Washington, DC: National Academy Press, 2001.

[4] Kramarski B, Mevarech ZR \& Lieberman A, "Effects of multilevel versus unilevel metacognitive training on mathematical reasoning," Journal Of Educational Research, vol. 94 no. 5pp. 292-301, 2001.

[5] Toole CM, Explaining math achievement by examining its relationships to ethnic background, gender, and level of formal reasoning. Unpublished Doctoral Thesis. Greensboro: The University of North Carolina, 2001.

[6] Battista MT, Wheatley GW \& Talsma G, "Spatial visualization, formal reasoning, and geometric problem-solving strategies of preservice elementary teachers," Focus on Learning Problems in Mathematics, vol. 11no. 4, pp.17-30, 1989.

[7] Revina, S., Design Research On Mathematics Education: Spatial Visualization Supporting Students' Spatial Structuring In Learning Volume Measurement, Unpublished Thesis. Universitas Sriwijaya, 2011.

[8] Duval R, "Geometry from a cognitive point of view," In C Mammana \& V Villani (eds). 16 Gunhan Perspectives on the Teaching of Geometry for the 21st Century: An ICMI Study. Dordrech: Kluwer, 1998.

[9] Battista MT, Wheatley GW \& Talsma G, The importance of spatial visualization andcognitive development for geometry learning in preservice elementary teachers. Journal for Research in Mathematics Education, vol. 13 no. 5, pp. 332-340, 1982. 
[10] Jones K, Critical Issues in the Design of the Geometry Curriculum. In B Barton (ed). Readings in Mathematics Education. Auckland: University of Auckland, 2000.

[11] Simon, Martin A, Reconstructing Mathematics Pedagogy from a Conswtructive Perspective, Journal of Research in Mathematics Education, vol 26 no. 2, pp. 135-137, 1995.

[12] Fauzan, A \& Yerizon, "Pengaruh Pendekatan RME dan Kemandirian Belajar Terhadap Kemamampuan Matematis Siswa," Prosiding Semirata FMIPA Universitas Lampung, 2013.

[13] Joubert, M and Andrews, P, "Using Realistic Mathematics Education with low to middle attaining pupils in secondary schools. Proceedings of the British Congress for Mathematics Education, 2010.

[14] Heuvel, Marja Van Den danPanhuizen, The Didactical Use of Models inRealistic Mathematics Education: an Example from A LongitudinalTrajectory on Percentage, 2003.

[15] Gravemeijer, Koeno and Cobb, Paul, "Design research from the Learning Design Perspective," in Jan Ven Den Akker, Educational Design Research, London: Routledge, 2006.

[16] Plomp, T and N. Nieveen, "Educational Design Research," Enshede: Netherlands Institute for Curriculum Development, 2013.

[17] Tessmer, M., Planning and Conducting Formatif Evaluation, London: Kogan Page, 1996 